\title{
Temperament and attachment as predictive factors for the risk of addiction to substances in adolescents
}

\author{
Maria G. Cornellà-Font, Ferran Viñas-Poch, Josep R. Juárez-López, María de las M. Martín-Perpiñá \\ and Sara Malo-Cerrato
}

Quality of Life Research Institute, Universidad de Gerona, Gerona, Spain

\begin{abstract}
This study aimed to examine relationship between dimensions of temperament and attachment with risk of addiction to substances in a group of 642 adolescents aged 13 to 19 years, and to assess what of these dimensions may act as risk or protective factors. There was a positive correlation between risk to addiction and the temperament dimension of "Novelty seeking", and with attachment dimensions "Self-sufficiency and parental resentment" and "Child trauma". The correlation was negative with "Persistence" (temperament) and "Security" (attachment). "Novelty seeking", "Family concern" and age seem to act as risk factors, whereas "Security" in attachment was a factor of protection. Temperament and attachment dimensions related with a higher risk of addiction significantly correlated with each other; low-risk profiles also correlated.
\end{abstract}

Keywords: Risk of addiction; temperament; attachment; adolescence.

Resumen: Temperamento y apego como factores predictivos para el riesgo de adicción a sustancias en adolescentes. Este estudio examina la relación de las dimensiones de temperamento y apego con el riesgo de adicción a sustancias en un grupo de 642 adolescentes con edades entre 13 y 19 años, y valorar qué dimensiones de estos constructos actúan como factores de riesgo o de protección. Encontramos una correlación positiva entre el riesgo de adicción y la dimensión de temperamento "Búsqueda de novedad", y con las de apego "Autosuficiencia y rencor hacia los padres" y "Trauma infantil". La correlación fue negativa con "Persistencia" (temperamento) y "Seguridad" (apego). "Búsqueda de la novedad", "Preocupación familiar" y edad, actuaron como factores de riesgo; mientras que la "Seguridad "en el apego fue un factor de protección. Los perfiles de temperamento y apego con riesgo más elevado de adicción correlacionaron significativamente entre síentre sí; también correlacionaron aquellos con riesgo bajo.

Palabras clave: Riesgo de adicción; temperamento; apego; adolescencia.

\section{Introduction}

There is a growing concern in several countries about the risky behaviours that appear during adolescence. Although many adolescents are in good health, the consumption of alcohol, drugs, or tobacco puts their physical and psychological health at risk (World Health Organization, 2018). If started during adolescence, this consumption is predictive of alcohol abuse and addiction

Recibido: 27 de febrero 2018; aceptado: 26 de junio 2018

Corresponding autor: Maria Gràcia Cornellà Font, Facultad de Psicología, Universidad de Gerona, Pujada de Sant Domènec, 9, 17004 Gerona, España. E-mail: u1027412@campus.udg.edu to toxic substances during adulthood (Ledoux, Sizaret, Hassler, \& Choquet, 2000; Pérez de Albéniz Garrote, Rubio Rubio, \& Madina Gómez, 2018). Alcohol and drug abuse are also risk factors for suicidal behaviour (Silva et al., 2017).

While risky behaviours have historically been evaluated from a biomedical or genetic perspective, factors related to the environment have also been taken into account (Jessor,1991). When analyzing socioemotional development, temperament and attachment theories have emerged as rivals, the former being linked to biological considerations and the latter to aspects related to the environment (Pierrehumbert, Miljkovitch, Plancherel, \& Halfon, 2000). 
Temperament is considered an innate construct that remains relatively stable throughout life (Chess \& Thomas, 1977), whereas the quality of the attachment to main caregivers during childhood is a predictor of an individual's social, emotional and cognitive development (Ainsworth, 1966). Some studies conclude that the type of parental care and of family environment have no effect on how temperament develops, it being considered to have a very important genetic component (Josefsson et al. 2013; Lee, Cloninger, Park, \& Chae, 2015). However, others indicate that the way in which security or insecurity in attachment is expressed, partially reflects aspects of temperament (Pierrehumbert et al., 2000). According to Goldsmith and Campos (1986), factors related to social context, such as the parents' educational style, control the expression of the temperament. From a genetic base, the person's interactions with different contexts builds relatively stable organization patterns that influence the management of emotions (Sanjuán, Guillén, \& PérezGarcía, 2018).

For some authors, such as Sroufe (1985) and Belsky \& Rovine (1987), attachment and temperament act as two independent constructs that affect different aspects of development. For others, such as Chess and Thomas (1982) and Thompson and Lamb (1984), attachment style is strongly influenced by a person's basic temperament. These authors are especially critical of theories positing that parents are almost exclusively responsible for how their children develop emotionally and psychologically.

According to Cloninger's model, temperament has four independent innate and hereditary dimensions (Cloninger, 2008). Of these, several studies highlight "novelty seeking" as the one most related to disorders of substance abuse or addiction (Zilberman, Tavares, \& El-Guebaly, 2003; Monras Arnau, Mondon, \& Jou Santacreu, 2008; Paulino, Pombo, Ismail, Figueir, \& Lesch, 2017); "Novelty seeking" would relate to behaviours of impulsivity and low frustration tolerance (Bagher Saberi Zafarghandi, Khanipour, \& Ahmadi, 2018), which relate, at their time, to substance abuse and to relapse to this abuse (Paulino et al., 2017; Pérez de Albéniz Garrote et al., 2018). On the other hand, high scores on the "persistence" scale would be related to a lower risk of addiction (Monras et al., 2008). People who use illegal drugs tend to score low on "reward dependence", while high scores on "harm avoidance" (along with a high score in novelty seeking) are shown in alcohol addicts; this temperamental profile is related to perception of novelty as appealing, but also as potentially harmful (Milivojevic et al., 2012).
The model outlined by Pierrehumbert (1996) focuses on the Internal Working Models (IWMs) first described by John Bowlby (1969), that comprise the set of behaviours through which the established style of attachment is expressed (Pinedo Palacios \& Santelices Álvarez, 2006). Emotions are thought to be regulated by means of IWMs (Miljkovitch, 2001). The three styles of attachment expressed through IWMs are secure, insecure (avoidant or ambivalent/resistant) (Ainsworth, 1979) and disorganized (Main \& Solomon, 1986).

Pierrehumbert's model proposes several dimensions that evaluate experiences from both the past and the present, as well as the personal interpretation of the attitudes of one's parents during childhood and the consequences these may have in the present (Miljkovitch, Pierrehumbert, Karmaiola, Bader, \& Halfon, 2005). Emotional deregulation is considered to be a risk factor for smoking, drug and alcohol abuse disorders (Schreiber, Grant, \& Odlaug, 2012; Ceyhan, Boysan, \& Kadak, 2018). It is also related to other problems that start during adolescence and late childhood, such as bullying (Magaz, Chorot, Sandín, Santed, \& Valiente, 2011). According to Miljkovitch et al. (2005), the type of experiences that individuals have with their attachment figures can be associated with the capability of regulating emotions. Addictive behaviours could be regarded as a counterproductive strategy to deal with problems of emotional regulation issued from attachment insecurities (Ceyhan et al., 2018). Such behaviours would appear as a secondary strategy to deactivate the attachment system, which activates in moments of emotional discomfort. The primary strategy is the search for contact with the attachment figure (Pierrehumbert et al., 2002; Harnic et al., 2010). In relation to this idea, several studies conclude that substance dependence is related (a) to the ambivalent/ resistant type of insecure style of attachment, represented in Pierrehumbert's model by the dimensions "family concern" and "parental interference" (Pierrehumbert et al., 2002; De Lucas, \& Montañés, 2006; Yuchang, Cuicui, Junxiu, \& Junyi, 2017), and (b) to low parental concern or "parental permissiveness", as is expressed in this model, and "child trauma" (Miljkovitch et al., 2005). Drug users score low on secure attachment cognitions (Miljkovitch et al., 2005).

The objectives of this study were: (1) to analyse the influence of temperament and attachment as possible risk factors of substance addiction, (2) to analyse which dimensions of these two factors, temperament and attachment, better predict the risk of substance addiction, and 3) to evaluate the extent to which temperament and attachment are related to each other. 


\section{Method}

\section{Participants}

The study was conducted on a total population of 5,247 secondary school students in the Alt Empordà region (Gerona, Spain). The multistage random cluster sampling technique was used, with the classroom as the cluster. An initial sample of 710 students were selected from the years comprising 3rd ESO (Obligatory Secondary School) to the final year of upper secondary. From this sample, 642 students $(90.4 \%)$ completed the questionnaires. The average age was $15.42(S D=1.27)$, comprising $290(45.2 \%)$ boys and $352(54.8 \%)$ girls (see Table 1).

Table 1. Socio demographic characteristics of the sample

\begin{tabular}{lcc}
\hline \multicolumn{1}{c}{ Variables } & $n$ & $\%$ \\
\hline Sex & & \\
Male & 290 & 45.2 \\
Female & 352 & 54.8 \\
\hline Age & & \\
13 & 24 & 3.7 \\
14 & 141 & 22.0 \\
15 & 164 & 25.5 \\
16 & 174 & 27.1 \\
17 & 109 & 17.0 \\
18 & 24 & 3.7 \\
19 & 6 & 0.9 \\
\hline School year & & \\
3rd ESO & 194 & 30.2 \\
4th ESO & 176 & 27.4 \\
1st year upper secondary & 159 & 24.8 \\
2nd year upper secondary & 113 & 17.6 \\
\hline
\end{tabular}

\section{Instruments}

Junior Temperament and Character Inventory (JTCI) (Luby, Svrakic, McCallum, Przybeck, \& Cloninger, 1999; Spanish version by Pelaz Antolín, Bayón Pérez, Fernández Líria, \& Rodríguez Ramos, 2010).The version of the Temperament and Character Inventory designed for children and adolescents has seven dimensions and a total of 108 dichotomous items $(0=$ true and $1=$ false $)$. Of the seven dimensions, four evaluate temperament and three evaluate character. On this occasion, we used only those of temperament, which have a total of 55 items. For this study, internal consistency (Cronbach's alpha) ranged from .57 for "reward dependence" and "persistence" to .77 for "harm avoidance"; it was .66 for "novelty seeking". These consistencies are very similar to those found by Pelaz Antolín et al. (2010).

Cartes, Models Individuelles de Rélation, short version (CaMir-R) (Pierrehumbert, 1996; Spanish version by Balluerka, Lacasa, Gorostiaga, Muela, \& Pierrehumbert, 2011). This short version of the CaMir test evaluates seven dimensions of attachment using thirty-two 5-point Likert-type response items $(1=$ totally disagree, $5=$ totally agree). Internal consistency (Cronbach's alpha) for this study was .87 for "security; availability and support of attachment figures", .90 for "family concern", .82 for "parental interference", .86 for "parental authority value", .69 for "parental permissiveness", .79 for "self-sufficiency and parental resentment" and .85 for "child trauma". The different dimensions used in this test are related to the various types of attachment described by Ainsworth (1979) and Main \& Salomon (1986), with "security; availability and support of attachment figures" being related to secure attachment; "family concern" and "parental interference" to the ambivalent/resistant type of insecure attachment; "self-sufficiency and resentment towards parents" to the avoidant type of insecure attachment; and, finally, "child trauma" to disorganized attachment. "Value of parental authority" and "parental permission" are related to representations of the family structure (Balluerka et al., 2011).

Youth Inventory-4 (YI-4) (Gadow \& Sprafkin, 1999; Spanish version by the same authors, 1999). This test consists of 120 items of 4-point Likert-type responses $0=$ never, $3=$ very often). The test parts from the classification of symptoms from the Diagnostic and Statistical Manual of Mental Disorders IV (DSM-IV), published by the American Psychological Association on 1994 to identify behavioural and emotional disorders in adolescents. On this occasion, only the $\mathrm{O}$ dimension was used, which consists of six items related to the consumption of substances and had an internal consistency (Cronbach's alpha) of .78 for this study. The YI-4 test admits two types of interpretation of its results, one by categories and the other by dimensions.

\section{Procedure}

After requesting the relevant permits from the Catalan Government's Department of Education and the heads of the participating schools, the latter were informed about the aims of the research and 
the anonymity and confidentiality of the data. The 18 schools in the region were contacted and six agreed to participate in the study, five state-run and one private. Once authorization was obtained from the schools, the questionnaires were administered to all the students in the classroom during school time. The participants received homogeneous and specific instructions on how to answer the questionnaires correctly. While they were doing this, instructors were present in the classroom to offer help or clarification.

The variable "risk of substance addiction" was calculated using the criteria described in the YI-4 test. According to these, risk cases were considered those adolescents who responded "often" or "very often" to the items "I drink alcohol" and "I smoke marihuana"; they were also considered at risk those who responded "sometimes", "often" or "very often" to the items "I use illegal drugs", "I get into trouble because I use drugs" and "I get into trouble because I drink alcohol". Those subjects who fulfilled the risk criteria from the YI-4 test (Gadow \& Sprafkin, 1999) were included in the category Risk of Substance Addiction.

\section{Statistical Analysis}

In order to work with more homogeneous age groups, 13 and 14-year-olds and 18 and 19-year olds were each placed in a single group, given that there were few subjects aged 13 and 19 . The chi-square test was used to analyse the distribution of the sample according to risk of substance addiction and to the socio demographic variables studied. In order to fulfil our first aim, correlations between the dimensions from the JTCI and CaMir-R tests and the dimensional evaluation of the YI-4 were calculated. In order to evaluate which dimensions related to temperament or attachment better predicted the risk of substance addiction, a binary logistic regression was performed using the forward step selection method (Wald). Finally, again through the use of correlations, the dimensions of temperament and attachment were compared. Statistical analysis of the data was carried out using the statistical package SPSS, version 22.0. The level of statistical significance required in all tests was $p<.05$.

\section{Results}

\section{Risk of substance addiction by sex and age}

Table 2 shows the frequency distribution for three of the items in group O of the YI-4 test, taking into account the sex and age of the subjects. These items are directly related to substance consumption.

According to the case definition, $19.5 \%$ of the sample studied was at risk of substance addiction. No differences were observed between the two sexes (see Table 3). An increase in risk was observed according to age, however, rising from a 7.9\% risk in subjects aged 13 to 14 to a $37.8 \%$ risk among the group of 18 to 19 -year olds. The risk also increased by school year, from $9.3 \%$ for students in 3 rd ESO to $24.8 \%$ for students in the final year of upper secondary.

Table 2. Responses to items in group O (Use of substances) on the YI-4.

\begin{tabular}{|c|c|c|c|c|c|c|c|c|c|c|c|c|}
\hline \multirow{2}{*}{ Items } & & \multicolumn{4}{|c|}{ Sex } & \multicolumn{7}{|c|}{ Age } \\
\hline & & & Male & & Fem. & $13-14$ & & 15 & & 16 & 17 & $18-19$ \\
\hline \multirow{4}{*}{$\begin{array}{l}\text { I drink } \\
\text { alcohol (beer, } \\
\text { wine, other } \\
\text { drinks) }\end{array}$} & 1 & 158 & $(55.83 \%)$ & 166 & $(47.42 \%)$ & $116(70.73 \%)$ & 93 & $(57.78 \%)$ & 68 & $(39.53 \%)$ & $34(31.77 \%)$ & $13(43.33 \%)$ \\
\hline & 2 & 90 & $(31.80 \%)$ & 139 & $(39.71 \%)$ & $38(23.17 \%)$ & 53 & $(32.92 \%)$ & 73 & $(42.44 \%)$ & $54(50.46 \%)$ & $11(36.67 \%)$ \\
\hline & 3 & 23 & $(8.12 \%)$ & 40 & $(11.43 \%)$ & $6 \quad(3.66 \%)$ & 12 & $(7.45 \%)$ & 22 & $(12.79 \%)$ & $18(16.82 \%)$ & $5(16.67 \%)$ \\
\hline & 4 & 12 & $(4.24 \%)$ & 5 & $(1.43 \%)$ & $(1.83 \%)$ & 3 & $(1.86 \%)$ & 9 & $(5.23 \%)$ & $1 \quad(0.93 \%)$ & $1 \quad(3.33 \%)$ \\
\hline \multirow{4}{*}{$\begin{array}{l}\text { I smoke } \\
\text { marihuana }\end{array}$} & 1 & 245 & $(86.57 \%)$ & 299 & $(85.43 \%)$ & $156(95.12 \%)$ & 144 & $(89.44 \%)$ & 142 & $(82.56 \%)$ & $81(75.70 \%)$ & $21(70.00 \%)$ \\
\hline & 2 & 22 & $(7.77 \%)$ & 39 & $(11.14 \%)$ & $4 \quad(2.44 \%)$ & 12 & $(7.45 \%)$ & 22 & $(12.79 \%)$ & $19(17.76 \%)$ & $4(13.33 \%)$ \\
\hline & 3 & 8 & $(2.83 \%)$ & 7 & $(2.00 \%)$ & $(0.61 \%)$ & 4 & $(2.48 \%)$ & 5 & $(2.91 \%)$ & $4 \quad(3.74 \%)$ & $1 \quad(3.33 \%)$ \\
\hline & 4 & 9 & $(3.18 \%)$ & 6 & $(1.71 \%)$ & $(1.83 \%)$ & 2 & $(1.24 \%)$ & 3 & $(1.74 \%)$ & $(2.80 \%)$ & $4(13.33 \%)$ \\
\hline \multirow{4}{*}{$\begin{array}{l}\text { I use illegal } \\
\text { drugs } \\
\text { (cocaine, } \\
\text { LSD, ecstasy, } \\
\text { etc.) }\end{array}$} & 1 & 274 & $(96.82 \%)$ & 345 & $(98.6 \%)$ & $157(95.73 \%)$ & 161 & $(99.38 \%)$ & 168 & $(97.67 \%)$ & $103(96.26 \%)$ & $(100 \%)$ \\
\hline & 2 & 6 & $(2.12 \%)$ & 4 & $(1.14 \%)$ & $4 \quad(2.44 \%)$ & 0 & $(0.00 \%)$ & 3 & $(1.74 \%)$ & $(2.80 \%)$ & $(0.00 \%)$ \\
\hline & 3 & 2 & $(0.71 \%)$ & 1 & $(0.28 \%)$ & $(0.61 \%)$ & 0 & $(0.00 \%)$ & 2 & $(1.16 \%)$ & $(0.00 \%)$ & $(0.00 \%)$ \\
\hline & 4 & 2 & $(0.71 \%)$ & 0 & $(0.00 \%)$ & $(0.61 \%)$ & 1 & $(0.62 \%)$ & 0 & $(0.00 \%)$ & $(0.00 \%)$ & $(0.00 \%)$ \\
\hline
\end{tabular}

Note. YI-4 = Youth Inventory-4. 1 = Never; 2 = Sometimes; 3 = Often; 4 = Very often. 
Table 3. Risk of substance addiction by sex, age and school year.

\begin{tabular}{lccc}
\hline \multicolumn{1}{c}{ Variables } & $n$ & $\%$ & $95 \% \mathrm{Cl}$ \\
\hline Sex & & & \\
$\quad$ Male & 54 & 18.6 & {$[14.2,23.1]$} \\
Female & 64 & 18.2 & {$[14.2,22.2]$} \\
\hline Age & & & \\
13 to 14 & 14 & 8.5 & {$[4.24,12.8]$} \\
15 & 25 & 15.2 & {$[9.7,20.69]$} \\
16 & 42 & 24.1 & {$[17.7,30.4]$} \\
17 & 27 & 24.8 & {$[16.7,32.9]$} \\
18 to 19 & 10 & 33.3 & {$[16.4,50.2]$} \\
\hline School year & & & \\
3rd ESO & 19 & 9.8 & {$[5.6,13.9]$} \\
4th ESO & 31 & 17.6 & {$[11.9,23.2]$} \\
1st year upper secondary & 40 & 25.1 & {$[18.4,31.8]$} \\
2nd year upper secondary & 28 & 24.8 & {$[16.8,32.7]$} \\
\hline
\end{tabular}

Correlation between the risk of substance addiction and the dimensions on the JTCI and CaMir-R

Regarding the dimensions related to temperament evaluated through the JTCI test, a positive and significant correlation was observed between "risk of substance addiction", evaluated dimensionally, and "novelty seeking". The correlation was equally significant, but in a negative sense, with "persistence". No significant correlations were observed for the dimensions "harm avoidance" and "reward dependence". When evaluating attachment, four dimensions from the CaMir-R test correlated significantly with "risk of substance addiction": "security; availability and support of attachment figures" and "value of parental authority" did so negatively, and "parental permissiveness", "self-sufficiency and parental resentment" and "child trauma" positively (see Table 4).

\section{Predictive variables of the risk of substance addiction}

The dimensions from the JTCI and CaMir-R tests and the socio demographic variables (sex, school year and age), were taken into account as predictor variables in a logistic regression using the forward step selection method (Wald). The variables that entered the equation in the various steps were as follows: in the first step, "novelty seeking" from the JTCI, entered as important risk factor; in the second step, age also entered as risk factor; in the third, "security; availability and support
Table 4. Correlation between risk of substance addiction and temperament and attachment dimensions.

\begin{tabular}{lc}
\hline \multicolumn{1}{c}{ Dimensions studied } & Risk of substance addiction \\
\hline JTCI & $.23^{* *}$ \\
Novelty seeking & -.05 \\
Harm avoidance & .01 \\
Reward dependence & $-.15^{* *}$ \\
Persistence & \\
\hline CaMir-R & $-.19^{* *}$ \\
Security; availability and support & \\
of attachment figures & -.00 \\
Family concern & .04 \\
Parental interference & $-.09^{*}$ \\
Value of parental authority & $.10^{*}$ \\
Parental permissiveness & $.11^{* *}$ \\
Self-sufficiency and parental & $.16^{* *}$ \\
resentment & Child trauma
\end{tabular}

Note. CaMir= Cartes, Models Individuelles de Rélation, short version; JTCI $=$ Junior Temperament and Character Inventory; $* * p<.01 ;{ }^{*} p<.05$

of attachment figures" from the CaMir-R entered as protective factor; and, finally, in the fourth step, "family concern", also from the CaMir-R, entered as risk factor. With a NagelkerkeR ${ }^{2}$ of .202, the model correctly classified $80.2 \%$ of the subjects. Table 5 shows the coefficients for the variables that entered each step.

\section{Correlation between the dimensions of temperament and those of attachment}

Three of the dimensions included in the CaMir- $\mathrm{R}$ correlated significantly with the four JTCI dimensions used in this study: "parental interference", "selfsufficiency and parental resentment" and "child trauma". The dimension of "security, availability and support of attachment figures" correlated significantly with all JTCI dimensions except for "harm avoidance". On the other hand, "parental permissiveness" did not correlate significantly with any of the JTCI dimensions. Table 6 shows all the correlation indexes.

\section{Discussion}

In the studied sample, we observed no differences regarding the risk of consumption according to sex, a 
Table 5. Results of logistic regression for risk of substance addiction.

\begin{tabular}{llrrrrrr}
\hline \multicolumn{1}{c}{ Variable } & \multicolumn{1}{c}{$B$} & E.T. & Wald & $g l$ & Sig. & $\operatorname{Exp}(\mathrm{B})$ \\
\hline Step 4(d) & Age & 0.42 & 0.09 & 20.98 & 1 & .00 & 1.52 \\
& Security (CaMir-R) & -0.58 & 0.15 & 14.14 & 1 & .00 & 0.56 \\
& Family concern (CaMir-R) & 0.43 & 0.17 & 6.36 & 1 & .01 & 1.54 \\
& Novelty seeking (JTCI) & 3.21 & 0.62 & 26.34 & 1 & .00 & 24.74 \\
& Constant & -8.74 & 1.72 & 25.74 & 1 & .00 & 0.00 \\
\hline
\end{tabular}

Note. CaMir= Cartes, Models Individuelles de Rélation, short version; JTCI= Junior Temperament and Character Inventory. a. Variable(s) introduced in Step 1: Novelty seeking (JTCI); b. Variable(s) introduced in Step 2: Age; c. Variable(s) introduced in Step 3: Security (CaMir-R); d. Variable(s) introduced in Step 4: Family concern (CaMir-R).

finding that was also highlighted by Ledoux et al. (2000). The aforementioned research stated that differences in consumption between the two sexes had been decreasing in preceding years. However, differences were observed in the risk of consumption according to age, which is postulated as risk factor.

If we take a look to the responses to the YI-4 test, we can see how alcohol was the substance of abuse of preference, at a level significantly higher than the other substances. It is also worth to take into account the fact that, even if age acted as risk factor (more age, more risk), the use of substances began alarmingly early. Not fulfilling the requirement to enter the risk of substance addiction category, nearly a quarter of the sample between 13 and 14 years old admitted consuming alcohol sometimes. For 16-year olds, if we take into account those who drink sometimes, often and very often, we are talking of more than the $60 \%$ of the sample; a $20 \%$ entered the category of risk. If the use of substances at early ages act as a factor of risk, as postulated by Ledoux et al.(2000) and the use of alcohol opens the door to other substances of abuse, as stated by Pérez de Albéniz-Garrote et al.(2018), and if it acts also as risk factor for suicidal behaviour, as appears in the study of Silva et al. (2017), those numbers should be taken into account in order to establish educational programs to change that tendency.

In response to the first aim of this study, which was to examine the relationship between the risk of substance addiction and the dimensions of temperament and attachment, we can confirm the correlation between the "novelty seeking" dimension and the risk of substance addiction, in line with the findings of other studies (Zilberman et al., 2013; Monras et al., 2008; Paulino et al., 2017). As observed in the aforementioned studies, we can also confirm that in our sample "Persistence" was the temperamental dimension to correlate most negatively with the risk of addiction. "Harm avoidance" and "reward dependence" were not related with the risk of substance addiction in this study, a different result to that found by Milivojevic et al. (2012), who stated

Table 6. Correlation between dimensions in the CaMir-R and JTCI.

\begin{tabular}{lcccc}
\hline \multirow{2}{*}{\multicolumn{1}{c}{ CaMir-R dimensions }} & \multicolumn{4}{c}{ JTCI dimensions } \\
\cline { 2 - 5 } & $\begin{array}{l}\text { Novelty } \\
\text { seeking }\end{array}$ & $\begin{array}{c}\text { Harm } \\
\text { avoidance }\end{array}$ & $\begin{array}{c}\text { Reward } \\
\text { dependence }\end{array}$ & Persistence \\
\hline Security; availability and support of attachment figures & $-.22^{* *}$ & -.05 & $.19^{* *}$ & $.17^{* *}$ \\
Family concern & $-.14^{* *}$ & $.27^{* *}$ & .06 & .08 \\
Parental interference & $.12^{* *}$ & $.23^{* *}$ & $-.14^{* *}$ & $-.15^{* *}$ \\
Value of parental authority & $-.21^{* *}$ & .04 & .06 & $.10^{*}$ \\
Parental permissiveness & .06 & -.02 & -.06 & -.02 \\
Self-sufficiency and parental resentment & $.19^{* *}$ & $.10^{*}$ & $-.27^{* *}$ & $-.16^{* *}$ \\
Child trauma & $.24^{* *}$ & $.16^{* *}$ & $-.18^{* *}$ & $-.20^{* *}$ \\
\hline
\end{tabular}

Note . $\mathrm{CaMir}=$ Cartes, Models Individuelles de Rélation, short version; JTCI= Junior Temperament and Character Inventory. $* * p<.01$; $* p<.05$ 
that low "reward dependence" was related to that risk. As exposed in the same study, "reward dependence" is related to the need of social approval (Milivojevic et al., 2012); the fact that in the present study the sample is based on adolescent population (Milivojevic's is based on adults), could explain a lower influence of the dictates of society. The attachment dimension "security; availability and support of attachment figures" displayed an important negative correlation with the risk of addiction. "Parental permissiveness", "self-sufficiency and parental resentment", and "child trauma" correlated positively with the risk of addiction. Thus, with respect to attachment, our results indicated a negative correlation with security in attachment and a positive one with insecure avoidant attachment, disorganized attachment and an ineffective family structure. These results coincide in part with those of the studies conducted by Pierrehumbert et al. (2002), Miljkovitch et al. (2005), De Lucas and Montañés (2006) and Yuchang et al. (2017), which found a higher risk of addiction to be related to insecure or disorganized attachment; in these studies, the correlation was considered to be greater with the ambivalent/resistant type of insecure attachment than with the avoidant one. Miljkovitch et al., in their study of 2005, also found that a lack of parental concern or "parental permissiveness" correlated with risk of addiction. The risk of substance addiction was therefore found to be affected by dimensions of both temperament and attachment.

Our second aim was to ascertain which temperamental and attachment dimensions act as risk factors and which as protective factors. Once again, the temperament dimension "novelty seeking" stood out, appearing as a very important risk factor that multiplied the risk of substance addiction by almost 25 . It is therefore a factor to take into account when diagnosing a possible addiction or in the approach to prevention programmes. The attachment dimension "family concern" appeared also as risk factor, multiplying the risk of addiction by 1.5 . The dimension "family concern" relates to the ambivalent/resistant type of insecure attachment, this time supporting the results of Pierrehumbert et al. (2002), Miljkovitch et al. (2005), De Lucas and Montañés (2006) and Yuchang et al. (2017). Age also acted as risk factor, a finding clearly perceived in exposure to the risk of addiction according to the socio demographic characteristics of the sample, and one which also coincides with the reflections already discussed in the study by Ledoux et al. (2000). As protective factor, attachment security appeared via "security; availability and support of attachment figures". Attachment security acted as a factor that can reduce the risk of addiction by a half, a result that was expected to be higher but that still should be taken into account when considering treatments or prevention, especially in relation to subjects who may be at risk due to their temperamental characteristics.

So, there's no doubt of the role of temperament as modulator of the risk of substance abuse via "novelty seeking". As for the attachment dimensions, it seems to be more decisive the fact of having an insecure or disorganised type of attachment than of having a secure one. Knowing that insecure attachment, especially the ambivalent/resistant type acts as risk factor for other psychosocial problems in adolescence, such as bullying, as stated by Magaz et al. (2011), establishes that the efforts should be directed to treat and improve the management of negative emotions by subjects with a non-secure type of attachment, for this management is what seems to have a protective role, according to Schreiber et al. (2012) and Ceyhan et al. (2018).

With respect to the third aim of this study, which focused on a possible relationship between the dimensions of temperament and attachment, we observed a relationship among temperamental profiles and types of attachment which were at his time related to risk of addition. The CaMir-R dimensions "parental interference", "self-sufficiency and parental resentment" and "child trauma", which represent respectively the ambivalent/resistant, avoidant and disorganized types of attachment (Balluerka et al. 2011), were highly related to "novelty seeking", but had a low correlation with "reward dependence" and "persistence". On the other hand, the CaMir-R dimension of "Security; availability and support of attachment figures", which states for secure attachment, had a low correlation with "novelty seeking", and a high one with "reward dependence" and "persistence". So, people who were at risk of addiction because of its temperamental profile (Milivojevic et al., 2012) seemed to be at risk also because of their attachment style (Miljkovitch et al. 2005).

Unable to know through this study how attachment and temperament affect each other, we can conclude that a relationship exists and that a secure type of attachment and a more protective temperament profile in front of risk of addiction are related; knowing how, could help when preventing that risk. The results open the door to further investigation on this relationship. Finally, we must take into account the limitations of this study, which include joint administration of the instruments and the small number of subjects aged between 18 and 19 , meaning a low representation of this age group in the study. Conducting a similar longitudinal study would allow these conclusions to be analysed in greater depth. 


\section{Conflicts of interest}

The authors have no conflicts of interest to declare.

\section{References}

Ainsworth, M. (1966). Reversible and irreversible effects of maternal deprivation on intellectual development. In Harvey O.J. (Ed.), Experience Structure \& Adaptability (pp. 149168). Berlin: Springer Nature.

Ainsworth, M. (1979). Infant-mother attachment. The American Psychologist, 34, 932-937.

American Psychiatric Association (1994). Diagnostic and statistical manual of mental disorders (4th ed.). Washington, DC: Author.

Bagher Saberi Zafarghandi, M., Khanipour, H., \& Ahmadi, S. M. (2018). Typology of substance use disorder based on temperament dimensions, typology of substance use disorder based on temperament dimensions, addiction severity, and negative emotions. Iranian Journal of Psychiatry, 13, 185-191.

Balluerka, N., Lacasa, F., Gorostiaga, A., Muela, A., y Pierrehumbert, B. (2011). Versión reducida del cuestionario CaMir (CaMir-R) para la evaluación del apego. Psicothema, $23,486-494$.

Belsky, J., \& Rovine, M. (1987). Temperament and attachment security in the strange situation: An empirical rapprochement. Child Development, 58, 787-795.

Bowlby, J. (1969). Attachment: Attachment and loss. Vol: 1. New York: Basic Books.

Ceyhan, E., Boysan, M., \& Kadak, M. T. (2018). Associations between online addiction, attachment style, emotion regulation, depression and anxiety in general population: Testing the proposed diagnostic criteria for internet addiction. Sleep and Hypnosis, 21, 123-139.

Chess, S., \& Thomas, A. (1977). Temperamental individuality from childhood to adolescence. Journal of the American Academy of Child Psychiatry, 16, 218-226.

Chess, S., \& Thomas, A. (1982). Infant bonding: Mystique and reality. American Journal of Orthopsychiatry, 52, 213-222.

Cloninger, C. R. (2008). The psychobiological theory of temperament and character: Comment on Farmer and Goldberg (2008). Psychological Assessment, 20, 292-299.

De Lucas Taracena, M. T., y Montañés Rada, F. (2006). Estilos y representaciones de apego en consumidores de drogas. Revista Adicciones, 18, 377-385.

Gadow, K. D., \& Sprafkin, G. (1999). Youth's Inventory 4 Manual. Stony Brook, N.Y.: Checkmate Plus.

Goldsmith, H., \& Campos, J. (1986). Fundamental issues in the study of early temperament: The Denver Twin Temperament Study. Advances in Developmental Psychology, 4, 231-283.

Harnic, D., Digiacomantonio, V., Innamorati, M., Mazza, M., Di Marzo, S., Sacripanti, F., Saioni, R., Cardella, A., Di Felice, C., Girardi, P. \& Janiri, L. (2010). Temperamento e attaccamento in pazienti con dipendenza da alcol di tipo $1 \mathrm{e}$ 2. Revista Di Psichiatria, 45, 311-319.

Jessor, R. (1991). Risk behavior in adolescence: A psychosocial framework for understanding and action. Journal of Adolescent Health, 12, 597-605.
Josefsson, K., Jokela, M., Hintsanen, M., Cloninger, C. R., PulkkiRåback, L., Merjonen, P., Hutri-Kähönen, N. \& KeltikangasJärvinen, L. (2013). Parental care-giving and home environment predicting offspring's temperament and character traits after 18 years. Psychiatry Research, 209, 643-651.

Ledoux, S., Sizaret, A., Hassler, C., \& Choquet, M. (2000). Consumo de sustancias psicoactivas en la adolescencia. Análisis de los estudios de cohorte. Adicciones, 12, 255-279.

Lee, S. J., Cloninger, C. R., Park, S. H., \& Chae, H. (2015). The association of parental temperament and character on their children's behavior problems. PeerJ, 3:e1464, 8-11.

Luby, J. L., Svrakic, D. M., McCallum, K., Przybeck, T. R., \& Cloninger, C. R. (1999). The Junior Temperament and Character Inventory: Preliminary validation of a child selfreport measure. Psychological Reports, 84, 1127-1138.

Magaz, A. M., Chorot, P., Sandín, B., Santed, M. A., y Valiente, R. M. (2011). Estilos de apego y acoso entre iguales (bullying) en adolescentes. Revista de Psicopatología y Psicología Clínica, 16, 207-221.

Main, M., \& Solomon, J. (1986). Discovery of an insecuredisorganized/disoriented attachment pattern. In T. B. Brazelton \& W. Yogman (Eds.), Affective development in infancy (pp. 95-124). Westport, CT: Ablex Publishing.

Milivojevic, D., Milovanovic, S. D., Jovanovic, M., Svrakic, D. M., Svrakic, N. M., Svrakic, S. M., \& Cloninger, C. R. (2012). Temperament and character modify risk of drug addiction and influence choice of drugs. American Journal on Addictions, 21, 462-467.

Miljkovitch, R. (2001). L'attachement au cours de la vie. Paris: Presses universitaires de France.

Miljkovitch, R., Pierrehumbert, B., Karmaiola, B., Bader, A., \& Halfon, O. (2005). Assessing attachment cognitions and their associations with depression in youth with eating or drug misuse disorders. Substance Use \& Misuse, 4, 605-623.

Monras Arnau, M., Mondon, S., \& Jou Santacreu, J. (2008). Using the temperament and character inventory (TCI) to predict outcome after inpatient detoxification during 100 days of outpatient treatment. Alcohol and Alcoholism, 43, 583-588.

Paulino, S., Pombo, S., Ismail, F., Figueira, M. L., \& Lesch, O. (2017). The role of affective temperament as a predictor of relapse in alcohol dependence. Personality and Mental Health, $11,278-289$.

Pelaz Antolín, A., Bayón Pérez, C., Fernández Líria, A., y Rodríguez Ramos, P. (2010). Invenatrio Infanto-Juvenil de Temperamento y Carácter. Revista de Psiquiatría InfantoJuvenil, 4, 319-330.

Pérez de Albéniz-Garrote, G., Rubio-Rubio, L., y Medina-Gómez, B. (2018). Papel moderador de los estilos parentales en la relación entre la impulsividad y el consumo de alcohol en una muestra de adolescentes españoles. Revista de Psicopatología y Psicología Clínica, 23, 47-57.

Pierrehumbert, B. (1996). Les modeles de relations. Developpement d'un autoquestionnaire d'attachement pour adultes. La Psychiatrie de L'enfant, 39, 161-206.

Pierrehumbert, B., Bader, M., Miljkovitch, R., Mazet, P., Amar, M., \& Halfon, O. (2002). Strategies of emotion regulation in adolescents and young adults with substance dependence or eating disorders. Clinical Psychology and Psycotherapy, 9, 384-394. 
Pierrehumbert, B., Miljkovitch, R., Plancherel, B., \& Halfon, O. (2000). Attachment and temperament in early childhood; Implications for later behavior problems. Infant and Child Development, 9, 17-32.

Pinedo Palacios, J. T., y Santelices Álvarez, M. P. (2006). Apego adulto: Los modelos operantes internos y la teoría de la mente. Terapia Psicológica, 24, 201-210.

Sanjuán, P., Guillén, D., y Pérez-García, A. M. (2018). Rasgos de personalidad y recursos psicológicos como predictores del bienestar emocional en adolescentes con y sin formación en escuelas de tauromaquia. Revista de Psicopatología y Psicología Clínica, 23, 1-12.

Schreiber, L. R. N., Grant, J. E., \& Odlaug, B. L. (2012). Emotion regulation and impulsivity in young adults. Journal of Psychiatric Research, 46, 651-658.

Silva, D., Valdivia, M., Vicente, B., Arévalo, E., Dapelo, R., y Soto, C. (2017). Intento de suicidio y factores de riesgo en una muestra de adolescentes escolarizados de Chile. Revista de Psicopatología y Psicología Clínica, 22, 33-42.
Sroufe, L. A. (1985). Attachment classification from the perspective of infant-caregiver relationships and infant temperament. Child Development, 56, 1-14.

Thompson, R. A., \& Lamb, M. E. (1984). Assessing qualitative dimensions of emotional responsiveness in infants: Separation reactions in the strange situation. Infant Behavior and Development, 7, 423-445.

Yuchang, J., Cuicui, S., Junxiu, A., \& Junyi, L. (2017). Attachment styles and smartphone addiction in chinese college students: The mediating moles of dysfunctional attitudes and selfesteem. International Journal of Mental Health and Addiction, 15, 1122-1134.

Zilberman, M. L., Tavares, H., \& El-Guebaly, N. (2003). Relationship between craving and personality in treatment-seeking women with substance-related disorders. BMC Psychiatry, 3, 1.

World Health Organization (2018). Adolescents: health risks and solutions. Retrieved from: http://www.who.int/news-room/ fact-sheets/detail/adolescents-health-risks-and-solutions 
